\title{
Derivative Analysis of Global Average Temperatures
}

\author{
Timothy Sands ${ }^{1}$ \\ ${ }^{1}$ Fu Foundation School of Engineering and Applied Science (CVN), Columbia University, New York, USA \\ Correspondence: Timothy Sands, Fu Foundation School of Engineering and Applied Science (CVN), Columbia \\ University, New York, USA.
}

Received: December 16, 2019

Accepted: January 15, 2020

Online Published: January 16, 2020

doi:10.5539/mas.v14n2p1

URL: https://doi.org/10.5539/mas.v14n2p1

\begin{abstract}
Contemporary climate studies are quite numerous, and the topic in general has become politically charged, where opposing political interests have generated juxtaposed studies with contradictory results despite near unanimous acceptance of the fact the planet is warning. One emotionally charged issue is whether the increase is man-made or naturally occurring. This study avoids political pitfalls and controversial postulations, instead seeking to add to the literature a mathematical catastrophe analysis based on derivative modelling and extrapolation to deduce whether an unexpected (sudden) rise or fall in dynamic global atmospheric temperatures (e.g. an ice age) is predicted by the dynamic atmospheric temperature data. The study concludes that extrapolations of a derivative model encounter an unstable equilibrium point at the end of this century leading to a prediction of the potential for a sudden, dramatic increase in global average temperatures. The author takes care not to make controversial predictions, instead merely follows the mathematical facts where they lead: The potential for a catastrophe if the unnamed causes of global temperature increases remain unaddressed.
\end{abstract}

Keywords: optimal modeling, derivative modeling, catastrophe analysis, deterministic artificial intelligence, global warming, climate change, heat wave, climate models

\section{Introduction}

\subsection{Introduce the Problem}

Univariate time series techniques presented in (Romilly, Peter, 2005) to model the properties of a global mean temperature dataset in order to develop a parsimonious forecasting model allows managerial decision-making over the short-term horizon. The estimation results confirmed the findings of a number of previous studies, namely that global mean temperatures increased significantly throughout the 20th century.

\subsection{Explore Importance of the Problem}

The definitive study (Vermeer, M., \& Rahmstorf, S., 2009) was published by the National Academy of Sciences revealing a simple relationship linking global sea-level variations on time scales of decades to centuries to global mean temperature. This relationship was tested on synthetic data from a global climate model for the past millennium and the next century (1880-2000), and the results affirmed prior studies.

\subsection{Describe Relevant Scholarship}

The causes of the rise of global average temperature in (Ring, M., Lindner, D., Cross, E., \& Schlesinger, M., 2009) was illustrated by using two independent methods to analyze the temperature measurements: Singular Spectrum Analysis and Climate Model Simulation. The concurrence of the results of the two methods, each using 13 additional years of temperature measurements from 1998 through 2010, shows humanity (not nature) has increased the Earth's global temperature since the 19th century. According to the study, humanity is also responsible for the most recent period of warming from 1976 to 2010 . Internal climate variability is primarily responsible for the early 20th century warming from 1904 to 1944 and the subsequent cooling from 1944 to 1976. The impacts of global warming and climate change via an increase in average global temperatures were studied in (Singh, B., \& Onkar, S., 2012), postulating natural events and human activities are main contributors to such increases in average global temperatures, for example rising emissions of carbon dioxide from vehicles, factories and power stations, emissions of carbon dioxide due to our use of fossil energy in general together leading to an estimated temperature increase by 2 to $6^{\circ}$ Celsius by the year 2100, They conclude the rise in planetary average temperatures are primarily caused by increases in "greenhouse" gases such as Carbon Dioxide (CO2), Nitrous 
oxide (NOX), Sulphur dioxide (SO2), Hydrogen etc.

\subsection{State Hypotheses and Their Correspondence to Research Design}

Following the definitive study by the National Academy of Science affirming the rise in global average temperatures and subsequent studies illustrating impacts, man-made causes, and correlating the temperature increase to specific chemical constituents, this manuscript investigates the potential for a sudden, precipitous catastrophic temperature rise by invoking system modeling from deterministic artificial intelligence as well as mathematical catastrophe analysis of derivative models. Catastrophe theory assumes a slow dynamic acts on the dominant fast dynamic indicated by the data. The slow dynamic can shift the curves of system models slowly until the derivative models cross zero, resulting in creation of a system equilibrium point. If the equilibrium point is stable, the temperature rise will suddenly cease, while an unstable equilibrium point indicates the potential for a precipitous, unexpected spike in temperatures akin a stock market crash. Catastrophe theory requires mathematical models, so the general method of deterministic artificial intelligence provides these dynamic atmospheric temperature models by first calculating optimal system models, then invoking the certainty equivalence principle to utilize the optimal models for atmospheric dynamics for predication of future conditions. Initial prediction by simple extrapolation sets the expectation for subsequent differentiation of dynamic atmospheric temperature models for catastrophe analysis. This application of the general method of deterministic artificial intelligence has proven effective for several classes systems (to be described in the next paragraph), and this manuscript uses the same techniques for predication of dynamic atmospheric temperature.

\section{Method}

\subsection{Self-Awareness}

Nonlinear adaptive identification and control techniques developed for space systems (Sands, T., Lorenz, R. 2009) (Sands, T., 2012) (Nakatani, S., 2014) (Sands, T., 2015) (Nakatani, S., 2016) (Sands, T., 2017) (Nakatani, S., 2018) (Smeresky, B., \& Rizzo, A., 2018) (Baker, K., Cooper, M., Heidlauf, P., \& Sands, T., 2018) (Heidlauf, P., \& Cooper, M., 2017) permitted innovative, new space missions (Sands, T., 2009) (Sands, T., 2018) (Sands, T., $\mathrm{Lu}, \mathrm{D}$., Chu, J., \& Cheng, B., 2018) by utilizing the governing physics (motion mechanics) to establish the deterministic self-awareness equations (math models to be adapted during operations). These techniques were initially applied merely to system identification for control, they quickly proved their efficacy applied to a myriad of component systems, both mechanical (Sands, T., Lu, D., Chu, J., \& Cheng, B., 2018) (Sands, T., Kim, J., \& Agrawal, B., 2006) (Sands, T., 2007). (Kim, J., Sands, T., \& Agrawal, B., 2007). (Sands, T., Kim, J., \& Agrawal, B., 2009) (Sands, T., Kim, J., \& Agrawal, B., 2012) (Sands, T., Kim, J., \& Agrawal, B., 2016) (Agrawal, B., Kim, J., \& Sands, T., 2017) (Sands, T., Kim, J., \& Agrawal, B., 2018) and electrical (Cooper, M., Heidlauf, P., \& Sands, T., 2017), culminating in a generalized methodology (Sands, T., 2017) of deterministic artificial intelligence. Applying the general methodology (referred to as deterministic artificial intelligence) to a disparate application, the key distinguishing feature is the choice of self-awareness equations. In the case of electrical systems (Cooper, M., Heidlauf, P., \& Sands, T., 2017), the governing physics (electro-mechanics) established the math models.

Following successful application of the general methodology to a wide range of applications (Sands, T., \& Kenny, T., 2017) (Sands, T., 2017) from piezo-electrics to sensors (Sands, T., 2018). and even digital manufacturing (Sands, T., \& Armani, C., 2018), the method most recently proved effective on time-series data (Sands, T., 2017) (Sands, T., 2018) for the sale of electric vehicles. Ref (Sands, T., \& Armani, C., 2018) compares more than one dozen variations of establishing self-awareness statements. Several of the methods utilize the underlying materials mechanics, while several other methods used standard 2-norm optimal curve fitting. Application to electrical vehicles sales in ref (Sands, T., 2017) (Sands, T., 2018) used standard curve fitting to establish the mathematical models, but then differentiated those models to permit catastrophe analysis to investigate the possibility of a sudden, dramatic change in the sales data caused by a slow-moving dynamic that drives the optimal mathematical models to an equilibrium point. In that case, a stable equilibrium point (resulting in sales dramatically falling to rest at zero) was the potential disaster.

Building on that success, this manuscript seeks to investigate the potential for a sudden catastrophic rise in dynamic atmospheric global average temperatures by first articulating system identification techniques for modeling to provide intuition, followed by derivative system analysis seeking future unstable equilibrium points. In this instance, unstable equilibrium points would indicate a sudden, dramatic rise (as opposed to a fall as seen with stable equilibrium points). 


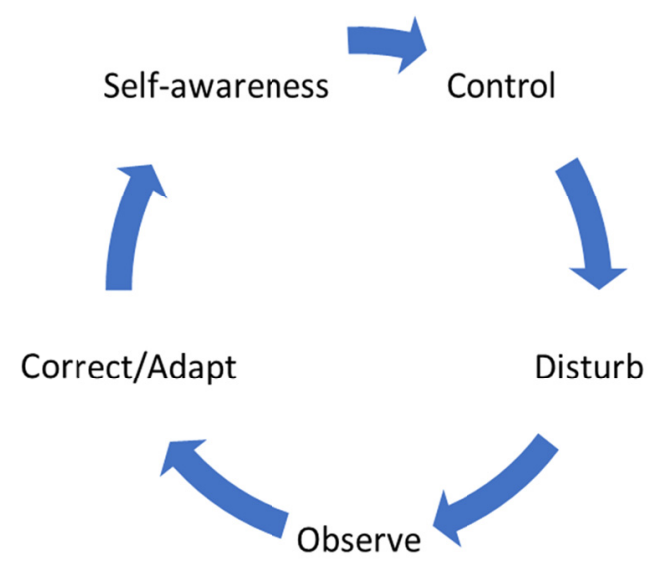

Figure 1. Deterministic artificial intelligence processes

\subsection{Control}

The motivation for finding the right self-awareness equations lies in the use of those equations for process control and decision-making. Establish control equations by invoking the certainty equivalence principle. Since that term has different definitions in disparate scientific fields, a definition in context of optimal estimation and optimal control follows.

Certainty equivalence principle: the optimal control is exactly the same as it would be if all unknowns were known and took values equal to their linear least square estimates (equivalently, their conditional means) based upon observations up to time t.

\subsection{Disturb}

After making decision and implementing process controls, natural processes disturb the process away from the idealized situation. These disturbances are not restricted to slow-moving dynamics associated with catastrophe analysis.

\subsection{Observe}

Process observation is key to driving towards the desired solution of the system equations. Especially in the cited references, the control is formulated explicitly using the self-awareness equations, so the action taken to correct the decision making process flow from observations of unexpected results followed by adaption of the self-awareness equations. The certainty equivalence principle applies to the observation as well as the correction/adaption steps of the deterministic artificial intelligence process.

\subsection{Correct/Adapt Self-Awareness}

Observations are used (by any chosen mathematical method) to correct the self-awareness equations, and afterwards the new, updated self-awareness equations are used for process control actions as before.

\subsection{Deterministic Artificial Intelligence Applied to Global Temperature Data}

Using average global temperature data (GISS Surface Temperature Analysis,2018) taken from the National Aeronautics and Space Administration, optimal system modeling produces several models of increasing order and increasing confidence. This methodology matches the methods of establishing self-awareness equations for both digital manufacturing and for time-series electrical vehicle sales.

\subsection{Catastrophe Analysis}

Intuition comes from time-propagation of the optimal system models via a simple mathematical approach. With this slight intuition (lacking any slow-moving dynamic), time-differentiation of the optimal system models reveals the rate of increase, but also the existence of equilibrium points is sought. Catastrophe analysis uses these derivative forms and imposes a slow-changing dynamic on the equation, while monitoring the effects on potential equilibrium points. Evaluation of equilibrium points as stable or unstable indicate cessation in the rise of average global temperatures or alternatively the potential for a sudden catastrophic temperature increase, respectively. Least squares in section 3.1 reveals optimal self-awareness equations, and these models are differentiated in section 3.2 to produce the mathematical models used in catastrophe analysis. 

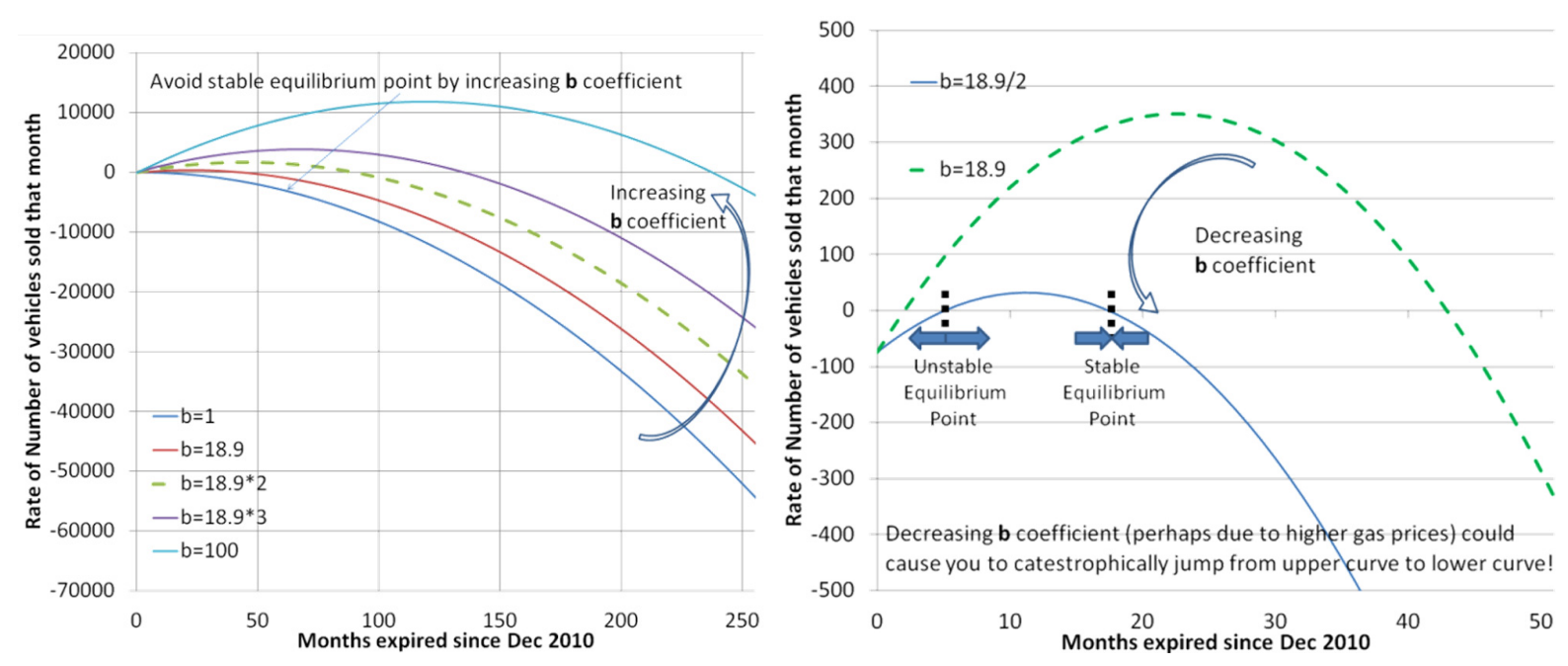

Figure 2. Sample evaluation of equilibrium points taken from (Sands, T., 2017) as self-awareness equation parameters are varied by an un-articulated slow-moving dynamic

Notice in Figure 2, normal application of catastrophe analysis imposes an known, slowly changing dynamic acting on the self-awareness parameters. The study in (Sands, T., 2017) determined that the b parameter was most sensitive to changes, and those changes resulted in potential creation of stable and unstable equilibrium points. In this research, it shall be seen that a slow-moving dynamic is not necessary. Upon time-derivative of the self-awareness equations, the possibility of equilibrium point creation will be immediately apparent.

\section{Results}

In the Results section, summarize the collected data and the analysis performed on those data relevant to the discourse that is to follow. Report the data in sufficient detail to justify your conclusions. Mention all relevant results, including those that run counter to expectation; be sure to include small effect sizes (or statistically nonsignificant findings) when theory predicts large (or statistically significant) ones. Do not hide uncomfortable results by omission. Do not include individual scores or raw data with the exception, for example, of single-case designs or illustrative examples. In the spirit of data sharing (encouraged by APA and other professional associations and sometimes required by funding agencies), raw data, including study characteristics and indivldual effect sizes used in a meta -analysis, can be made available on supplemental online archives.

Following the methods described in section 2, section 3.1 begins with enumeration of the optimal system models for equations of increasing order and coefficient of determination for current data followed by extrapolation of the data to predict behavior of the models throughout this century. Next, in section 3.2 optimal derivative models are developed to permit mathematical catastrophe analysis, where equilibrium points of the derivative models are sought and evaluated as stable or non-stable.

\subsection{Optimal System Equations}

Well known 2-norm optimization procedures (Sands, T., 2017) (Sands, T., 2018) are used to fit the recorded data to equations of increasing order. Linear (1st order) equations reveal the general trend of the data, while increasingly sophisticated equations account for higher order dynamics.

\subsubsection{Years $1880-2018$}

Equations 1-6 display the optimal models for equations of increasing mathematical order, while the respective coefficients of determination are shown in table 1 . The recorded data together with the model-predicted data are displayed together in figure 1, where the coefficient of determination, indicating how well observed outcomes are replicated by the model, based on the proportion of total variation of outcomes explained by the model, as listed in table 1. At this point, we see that no notable accuracy improvement results from increasing model order from 5 to 6 . Thus, nominal time-series analysis of the data would indicate the 5th order model is sufficient, and no precipitous temperature increase seems likely. Both assertions will prove incorrect section 3.2 will use catastrophe analysis of derivative models, illustrating the justification for merely asserting that time-series analysis in this manuscript merely provides a context for subsequent analysis, as opposed to being the basis of conclusions about the data. In the equations in this manuscript, $\mathrm{T}$ is the average monthly global temperature in a 
given year, $\mathrm{Y}$.

$$
\begin{gathered}
T=0.0094 Y-18.206 \\
T=9 \times 10^{-5} Y^{2}-0.3224 Y+304.94 \\
T=1 \times 10^{-6} Y^{3}-0.0067 Y^{2}+12.809 Y-8222 \\
T=1 \times 10^{-8} Y^{4}-7 \times 10^{-5} Y^{3}+0.2149 Y^{2}-274.98 Y+131926 \\
T=-6 \times 10^{-10} Y^{5}+6 \times 10^{-6} Y^{4}-0.0244 Y^{3}+47.533 Y^{2}-46367 Y+2 \times 10^{7} \\
T=2 \times 10^{-12} Y^{6}-2 \times 10^{-8} Y^{5}+0.0001 Y^{4}-0.2771 Y^{3}-416.87 Y^{2}-334168 Y+1 \times 10^{8}
\end{gathered}
$$

Table 1. Coefficient of determination, $\mathrm{R}^{2}$ for optimal models

\begin{tabular}{cccccc}
\hline $1^{\text {st }}$ order & $2^{\text {nd }}$ order & $3^{\text {rd }}$ order & $4^{\text {th }}$ order & $5^{\text {th }}$ order & $6^{\text {th }}$ order \\
\hline 0.7992 & 0.8843 & 0.9037 & 0.9054 & 0.9143 & 0.9143 \\
\hline
\end{tabular}

Note. $R^{2} \equiv 1-\frac{\text { residual sum of squares }}{\text { total sum of squares }}$

\subsubsection{Years $1880-2100$}

Simple extrapolation of equations (1)-(6) to the end of the century provides some initial insight to set our expectations for more sophisticated catastrophe analysis, and the results are displayed in figure 2. The "raw data" is extrapolated simply by using the $1^{\text {st }}$ order slope as the rate of change to predict the next months expected raw data. Notice the $4^{\text {th }}$ order system model seems to indicate a precipitous drop in temperatures at the turn of the century, while the $5^{\text {th }}$ order system model predicts a continued steady climb. The $6^{\text {th }}$ order system equations indicate a precipitous rise in temperatures at the turn of the century. Later, in section 3.2 attention will be drawn on the results of catastrophe analysis on the optimal derivative models of $3^{\text {rd }}, 4^{\text {th }}, 5^{\text {th }}$, and $6^{\text {th }}$ order.

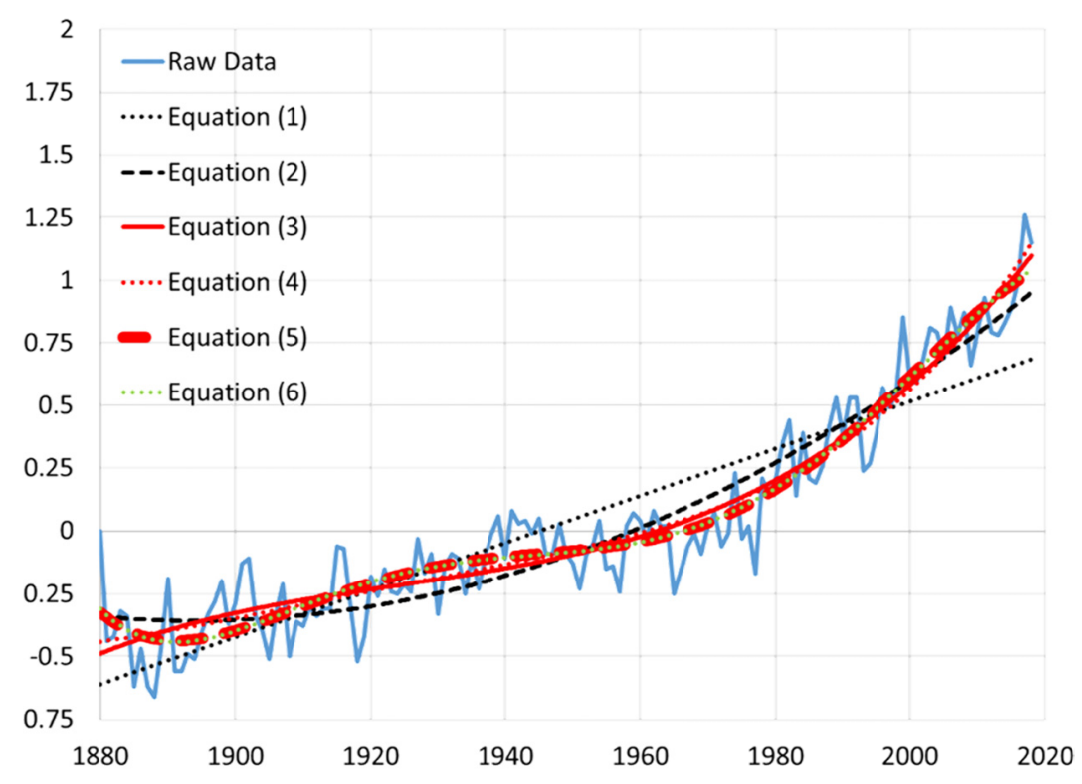

Figure 1. Optimal system models of increasing order for the years 1880-2018 


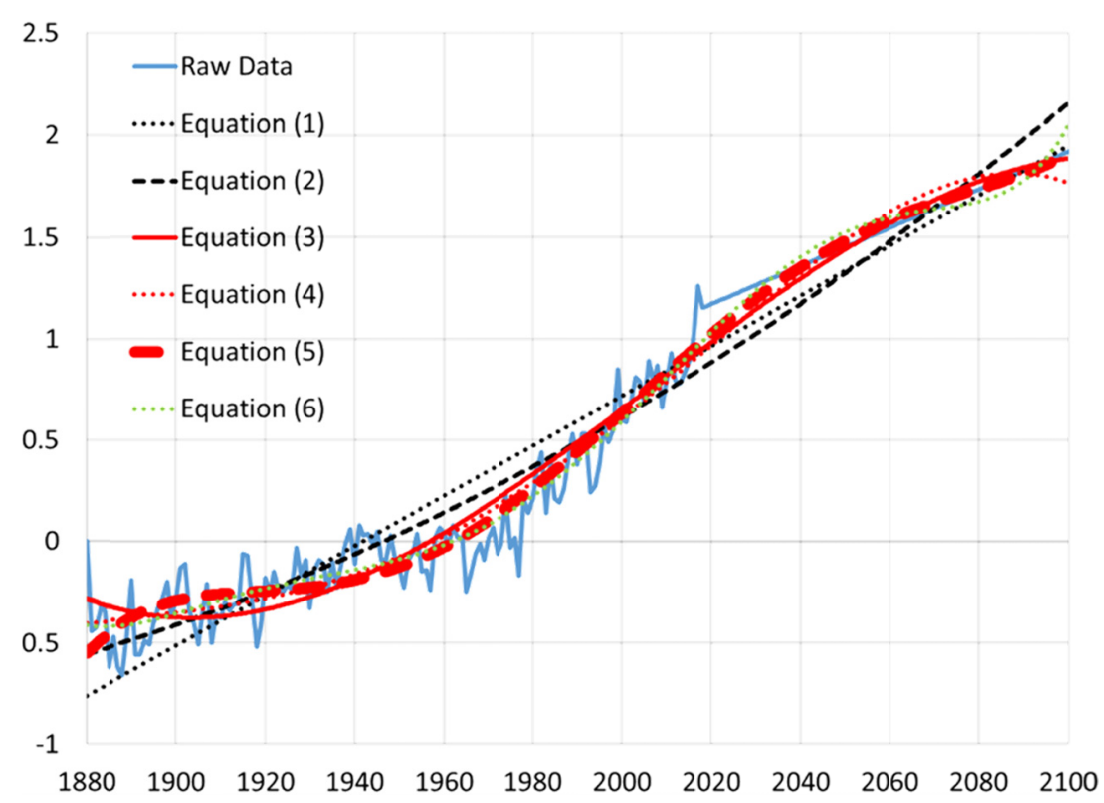

Figure 2. Extrapolated optimal system equations for models of increasing order for years 1880-2100

\subsection{Optimal Derivative Models}

Time-differentiation (with respect to years) of equations (1)-(6) produce equations (7)-(12). These equations represent the time-rate-of-change of the temperature data. An important notion of catastrophe analysis is the seek equilibrium points of the derivative models, and subsequently evaluate the stability or instability of the equilibrium points. Catastrophe analysis assumes an unknown slow-dynamic acting on the dominant fast-dynamic embodied in equations (1)-(6). This slow-dynamic can cause a system that was climbing to (for example) reach a stable equilibrium point unexpectedly. The stable equilibrium point would cause a catastrophic and unexpected fall in the data, despite a steady climb leading up to the point before the equilibrium point is encountered. The opposite is also possible, where a steadily falling system could encounter an unstable equilibrium point that causes a sudden (surprising), catastrophic increase.

$$
\begin{gathered}
\frac{d T}{d t}=0.0094 \\
\frac{d T}{d t}=15 \times 10^{-5} Y-0.3224 \\
\frac{d T}{d t}=3 \times 10^{-6} Y^{2}-0.0134 Y+12.809 \\
\frac{d T}{d t}=4 \times 10^{-8} Y^{3}-21 \times 10^{-5} Y^{2}+0.4298 Y-274.98 \\
\frac{d T}{d t}=-30 \times 10^{-10} Y^{4}+24 \times 10^{-6} Y^{3}+142.599 Y^{2}-0.0732 Y-46367 \\
\frac{d T}{d t}=12 \times 10^{-12} Y^{5}-10 \times 10^{-8} Y^{4}+0.0004 Y^{3}-0.8313 Y^{2}-833.74 Y-334168
\end{gathered}
$$

\subsubsection{Years 1880-2018}

The results of equations (9)-(12) are plotted in figure 3 for the highest four orders of equations. Catastrophe analysis is normally reserved for models of third-order form (at least) whose derivatives are therefore second order at least (and therefore we commence with equation 9). None of the derivative models in figure 3 cross zero, so no equilibrium points have been seen in the years 1880-2018. Notice that even a dramatic slow-dynamic imposed on the system would not likely produce equilibrium points, since shifting the curves slightly higher/lower (or even dramatically higher/lower) would not result in zero-crossings. 


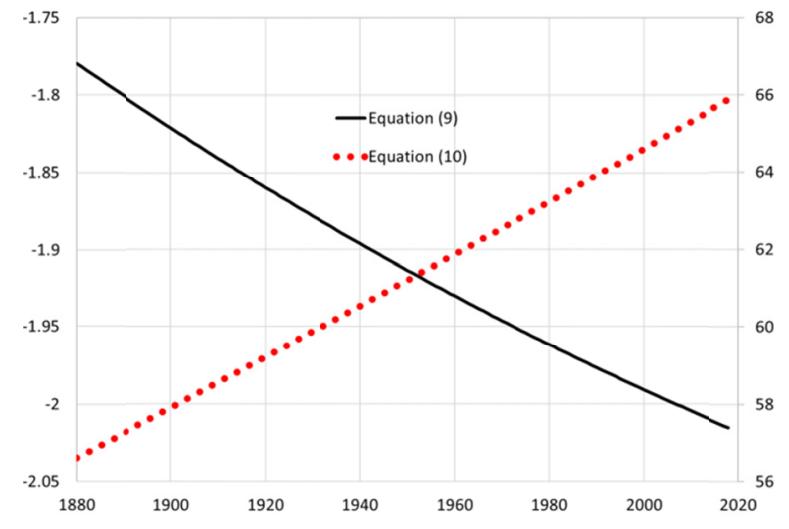

(a) Third and fourth order derivative models

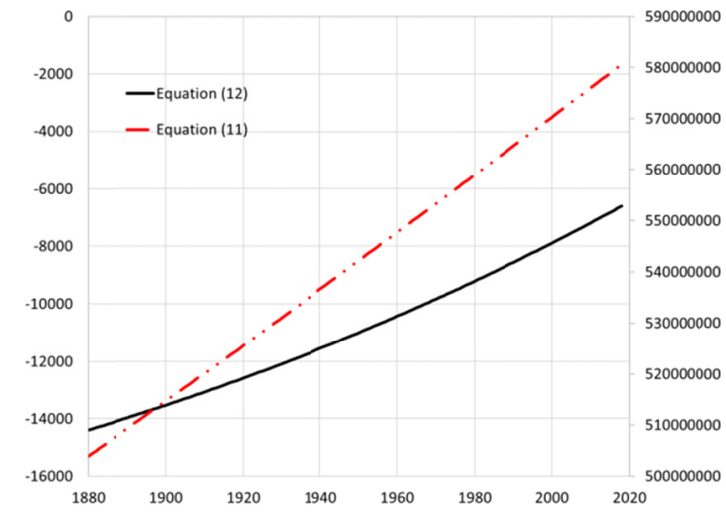

(b) Fifth and sixth order derivative models

Figure 3. Optimal derivative models: equations (10) and (11) are read using the second y-axes on the right

\subsubsection{Years $1880-2100$}

Next, derivative models are extrapolated to the end of the century as displayed in figure 4a. Notice that even a dramatic slow-dynamic imposed on the systems in figure 4a would not likely produce equilibrium points, since shifting the curves slightly higher/lower (or even dramatically higher/lower) would not result in zero-crossings. It is interesting to note the fourth order system model whose third order derivative form reveals a steadily increasing temperature throughout the entire century, but does not cross zero, and thus does not encounter an equilibrium point (either stable or unstable). Thus a realistic prediction would be steady temperature rise, but no catastrophe. On the other hand, figure $4 \mathrm{~b}$ displays a zero-crossing (even without imposition of a slow-moving dynamic), and therefore an equilibrium point are encountered. If the points is unstable, a catastrophic, unexpectedly sharp increase in temperature would be indicated as a potential at the end of the century. Figure 5 illustrates that indeed the equilibrium point is unstable.

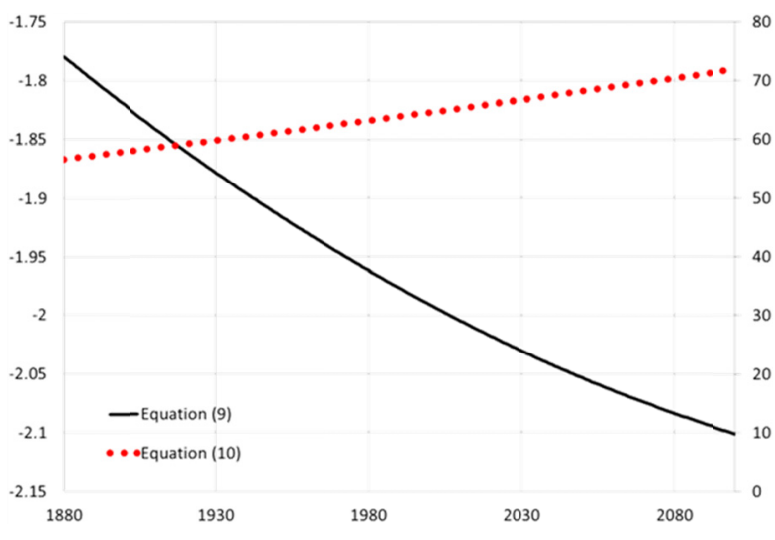

(a) Third and fourth order models

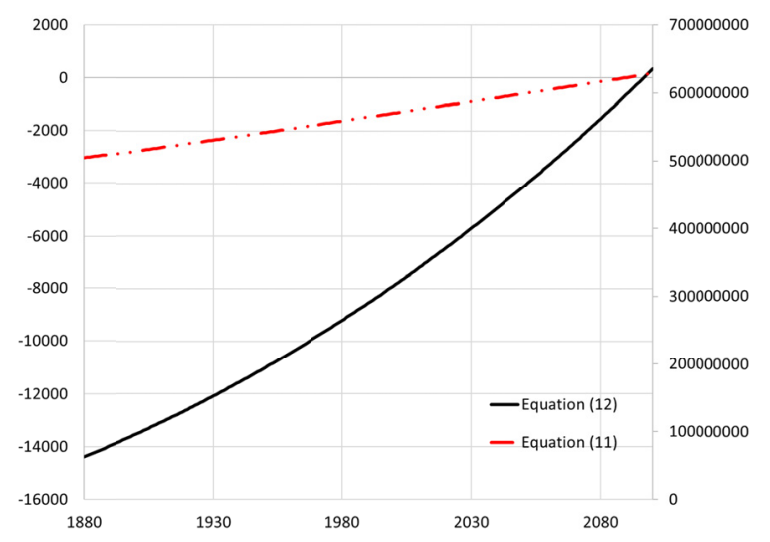

(b) Fifth and sixth order models

Figure 4. Extrapolated optimal derivative models: equations (10) and (11) are read using the second $y$-axes on the right 


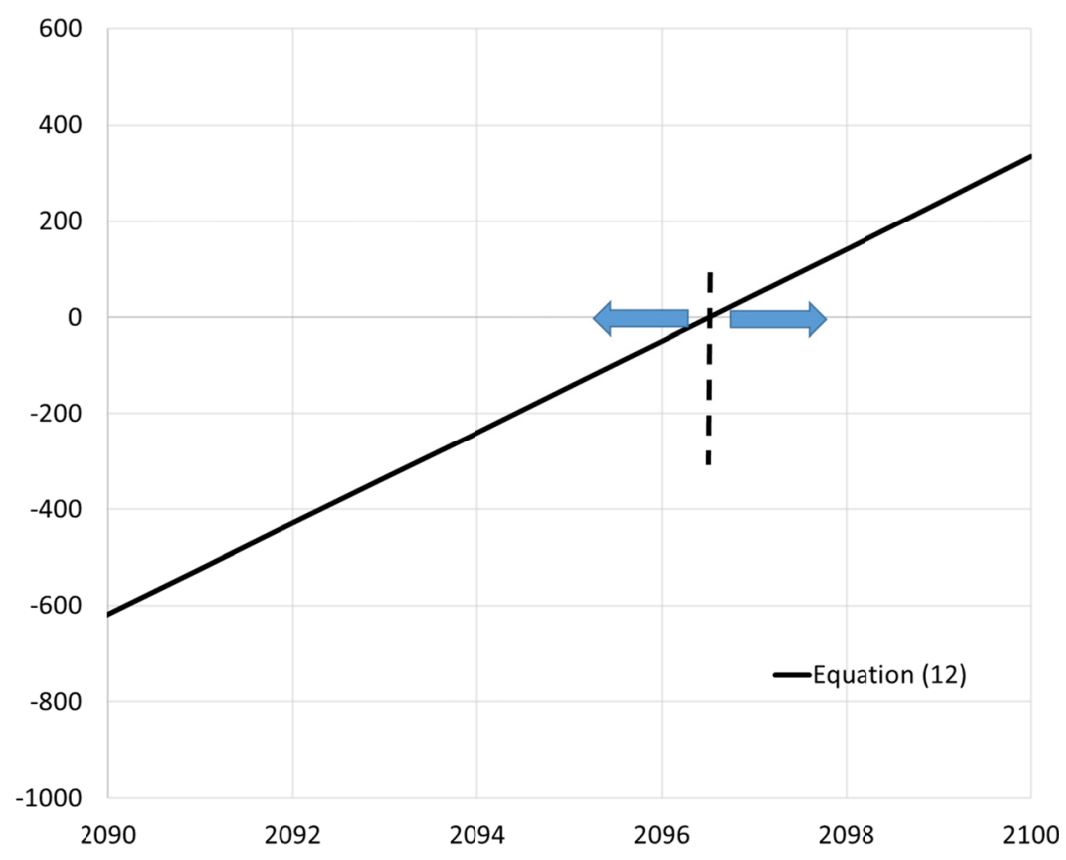

Figure 5. Unstable equilibrium point in the year 2096

\section{Discussion}

The results of this research further reinforce many previous studies but go further to reveal a potential catastrophe just prior to the turn of the century (assuming the causes listed in the references remain, e.g. hydrocarbon fuel use, accumulation of carbon dioxide, and others). All models investigated illustrate consistently increasing temperatures, while the derivative model with the highest confidence indicates an unstable equilibrium point that could lead to a jump discontinuity, where a seemingly unexplained sudden spike in temperature was revealed by catastrophe analysis of the average global temperature data since the year 1880 .

Future research should include efforts to correlate causes of temperature increase to the variable coefficients in the models, leading to the ability take the most effective corrective actions to avoid the catastrophe. This is a key second step in deterministic artificial intelligence methods, especially when the dynamics atmospheric models are derived using empirical data (invoking the certainly equivalence principle); instead of using dynamic models from physics-based equations, where certainty equivalence is unnecessary. Furthermore, periodic repetition of the catastrophe analysis should be performed with newly evolving data to monitor the slowly changing dynamic associated with catastrophe theory.

\subsection{Future Research}

The formative research does not analyze estimation errors of the polynomial coefficients, instead merely accepts very high correlation coefficients (exceeding 0.9) as indications of very high correlation (yet not causal). Interesting future research also includes investigation of the efficacy of penalized splines replacing polynomial forms. While this research has its basis in deterministic (non-stochastic) artificial intelligence methods, it remains of interest to compare these results to a stastistical study of the errors and uncertainty to aid the reader ascertain reliability of conclusions indicated here.

\section{Acknowledgments}

Professor Sands is not a tenured faculty member of Stanford or Columbia University; rather he is the Associate Dean of the Naval Postgraduate School's Graduate School of Engineering and Applied Sciences. In order to avoid legal jeopardy, Dr. Sands publishes government-funded research under his association with the Naval Postgraduate School, while publishing non-government funded research under his continuing associations with Stanford and Columbia Universities. The education that lead to this self-funded research was funded by the U.S. Strategic Command's distance learning education program (Mihalik, R., Camacho, H., \& Sands, T., 2018) (Sands T., Camacho, H., \& Mihalik, R., 2017) in response to an increased need for critical thinking in the nuclear enterprise in a period of global uncertainty (Bittick, L., \& Sands, T., 2019) (Sands, T., Camacho, H., \& Mihalik, 
R., 2018) (Nakatani, S., \& Timothy Sands, T., 2018) (Sands, T., \& Mihalik, R., 2016) (Sands, T., Mihalik, R., \& Camacho, H., 2018). The APC was funded by corresponding author.

\section{References}

Agrawal, B., Kim, J., \& Sands, T. (2017). Method and apparatus for singularity avoidance for control moment gyroscope (CMG) systems without using null motion, U.S. Patent 9567112 B1, Feb 14, 2017.

Baker, K., Cooper, M., Heidlauf, P., \& Sands, T. (2018). Autonomous trajectory generation for deterministic artificial intelligence. Elec. and Electr. Eng., 8(3), 59-68.

Bittick, L., \& Sands, T. (2019). Political Rhetoric or Policy Shift: A Contextual Analysis of the Pivot to Asia. Journal of Social Sciences, 15, 92-125. https://doi.org/10.3844/jssp.2019.92.125

Cooper, M., Heidlauf, P., \& Sands, T. (2017). Controlling Chaos-Forced van der Pol Equation. Mathematics on

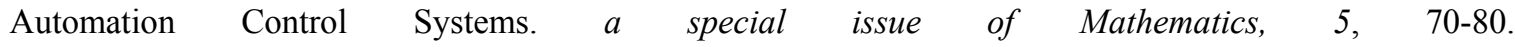
https://doi.org/10.3390/math5040070

GISS Surface Temperature Analysis. (GISTEMP). National Aeronautics and Space Administration Goddard Institute for Space Studies website: https://data.giss.nasa.gov/gistemp/, Page updated: 2018-09-24 20:43. Accessed on 20 October 2018.

Heidlauf, P., \& Cooper, M. (2017). Nonlinear Lyapunov Control Improved by an Extended Least Squares Adaptive Feed forward Controller and Enhanced Luenberger Observer, In Proceedings of the International Conference and Exhibition on Mechanical \& Aerospace Engineering, Las Vegas, NV, USA, 2-4 October 2017.

Kim, J., Sands, T., \& Agrawal, B. (2007). Acquisition, tracking, and pointing technology development for bifocal relay mirror spacecraft. Proc. SPIE, 6569. https://doi.org/10.1117/12.720694

Mihalik, R., Camacho, H., \& Sands, T. (2018). Continuum of Learning: Combining Education, Training, and Experiences. Education,. 8(1), 9-13.

Nakatani, S. (2014). Simulation of spacecraft damage tolerance and adaptive controls, Proc. IEEE Aero., 1-16. https://doi.org/10.1109/AERO.2014.6836260

Nakatani, S. (2016). Autonomous damage recovery in space. Intl. J. Auto. Contr. Intell. Sys., 2(2), 22-36. ISSN Print: 2381-75.

Nakatani, S. (2018). Battle-damage tolerant automatic controls. Elec. and Electr. Eng., 8, 10-23.

Nakatani, S., \& Timothy Sands, T. (2018). Eliminating the Existential Threat from North Korea. Science and Technology, 8(1), 11-16. doi: 10.5923/j.scit.20180801.02.

Ring, M., Lindner, D., Cross, E., \& Schlesinger, M. (2012). Causes of the Global Warming Observed since the 19th Century. Atmospheric and Climate Sciences, 2, 401-415. https://doi.org/10.4236/acs.2012.24035

Romilly, Peter. (2005). Time series modeling of global mean temperature for managerial decision-making. Journal of environmental management, 76, 61-70. https://doi.org/10.1016/j.jenvman.2005.01.008

Sands, T. (2007). Fine Pointing of Military Spacecraft. Ph.D. Dissertation, Naval Postgraduate School, Monterey, CA, USA, 2007.

Sands, T. (2009). Satellite Electronic Attack of Enemy Air Defenses. Proc. IEEE SEC, 434-438. https://doi.org/10.1109/SECON.2009.5174119

Sands, T. (2012). Physics-based control methods. Adv. Space. Sys. Orb. Det., InTech, London. https://doi.org/10.5772/2408

Sands, T. (2015). Improved Magnetic Levitation via Online Disturbance Decoupling. Physics Journal, 1(3) 272-280, 2015.

Sands, T. (2017). Phase Lag Elimination At All Frequencies for Full State Estimation of Spacecraft Attitude. Physics Journal, 3(1), 1-12.

Sands, T. (2017). Nonlinear-adaptive mathematical system identification. Computation, 5, 47-59. https://doi.org/10.3390/computation5040047

Sands, T. (2017). Space systems identification algorithms. J. Space Expl., 6, 138-149. ISSN: 2319-9822.

Sands, T. (2017). The Catastrophe of Electric Vehicle Sales. Mathematics 2017, 5, 46. https://doi.org/10.3390/math5030046 
Sands, T. (2018). Electric Vehicle Sales Catastrophe Averted by Deterministic Artificial Intelligence Methods. Submitted to Applied Mathematics, 9(1), 2018.

Sands, T. (2018). Experimental Sensor Characterization. J. Space Expl. 7(1), 140.

Sands, T. (2018). Space mission analysis and design for electromagnetic suppression of radar. Intl. J. Electromag. and Apps., 8, 1-25. .

Sands, T., \& Armani, C. (2018). Analysis, correlation, and estimation for control of material properties. J. Mech. Eng. Auto., 8, 7-31.

Sands T., Camacho, H., \& Mihalik, R. (2017). Education in Nuclear Deterrence and Assurance. $J$ Def Manag, 7 , 166. https://doi.org/10.4172/2167-0374.1000166

Sands, T., Camacho, H., \& Mihalik, R. (2018). Nuclear Posture Review: Kahn Vs. Schelling and Perry. Journal of Social Sciences, 14, 145-154. https://doi.org/10.3844/jssp.2018.145.154

Sands, T., Kim, J., \& Agrawal, B. (2006). 2H Singularity free momentum generation with non-redundant control moment gyroscopes. Proc. IEEE CDC., 1551-1556. https://doi.org/10.1109/CDC.2006.377310

Sands, T., Kim, J., \& Agrawal, B. (2009). Control moment gyroscope singularity reduction via decoupled control. Proc. IEEE SEC., 1551-1556. https://doi.org/10.1109/SECON.2009.5174111

Sands, T., Kim, J., \& Agrawal, B. (2012). Nonredundant single-gimbaled control moment gyroscopes. J. Guid. Dyn. Contr., 35, 578-587. https://doi.org/10.2514/1.53538

Sands, T., Kim, J., \& Agrawal, B. (2016). Experiments in Control of Rotational Mechanics. Intl. J. Auto. Contr. Intel. Sys., 2, 9-22. ISSN: 2381-7534.

Sands, T., Kim, J., \& Agrawal, B. (2018). Singularity Penetration with Unit Delay (SPUD). Mathematics, 6, 23-38. https://doi.org/10.3390/math6020023

Sands, T., \& Kenny, T. (2017). Experimental piezoelectric system identification. J. Mech. Eng. Auto, 7, 179-195. DOI: $10.5923 /$ j.jmea.20170706.01.

Sands, T., \& Lorenz, R. (2009). Physics-Based Automated Control of Spacecraft. Proceedings of the AIAA Space 2009 Conference and Exposition, Pasadena, CA, USA, 14-17 September 2009. https://doi.org/10.2514/6.2009-6625

Sands, T., Lu, D., Chu, J., \& Cheng, B. (2018) Developments in Angular Momentum Exchange. International Journal of Aerospace Sciences, 6(1), 1-7.

Sands, T., \& Mihalik, R. (2016). Outcomes of the 2010 \& 2015 Nonproliferation Treaty Review Conferences. World Journal of Social Sciences and Humanities, 2(2), 46-51.

Sands, T., Mihalik, R., \& Camacho, H. (2018). Theoretical Context of the Nuclear Posture Review. Journal of Social Sciences, 14, 124-128. https://doi.org/10.3844/jssp.2018.124.128

Singh, B., \& Onkar, S. (2012). Study of Impacts of Global Warming on Climate Change: Rise in Sea Level and Disaster Frequency, Chapter 3 in Global Warming - Impacts and Future Perspective, InTech Publishers, September 19, 2012. https://doi.org/10.5772/50464

Smeresky, B., \& Rizzo, A. (2018). Kinematics in the Information Age. Mathematics and Engineering. special issue in Mathematics, 6(9), 148. https://doi.org/10.3390/math6090148

Vermeer, M., \& Rahmstorf, S. (2009). Global sea level linked to global temperature. Proceedings of the National Academy of Sciences, 106(51), 21527-21532. https://doi.org/10.1073/pnas.0907765106

\section{Copyrights}

Copyright for this article is retained by the author(s), with first publication rights granted to the journal.

This is an open-access article distributed under the terms and conditions of the Creative Commons Attribution license (http://creativecommons.org/licenses/by/3.0/). 